\title{
Peningkatan Pengetahuan Masyarakat Cikupa Terhadap Tuberkulosis
}

\author{
Zita Atzmardina ${ }^{1 *}$, Like Splendya ${ }^{2}$, Jessica Englo ${ }^{3}$, \\ Graciela Aprilia Djohan ${ }^{4}$, Arnolda Lepang Makin ${ }^{5}$ \\ ${ }^{1}$ Bagian Ilmu Kesehatan Masyarakat, Fakultas Kedokteran Universitas Tarumanagara, Jakarta, Indonesia \\ ${ }^{2345}$ Mahasiswa Fakultas Kedokteran Universitas Tarumanagara, Jakarta \\ Author E-mail: zitaa@fk.untar.ac.id
}

\section{A B S T R A K}

\section{Latar belakang}

Tuberkulosis (TB) masih menjadi salah satu masalah kesehatan di masyarakat yang dapat menimbulkan kesakitan, kecacatan dan kematian yang tinggi sehingga perlu dilakukan upaya penanggulangan. Infeksi akan terjadi ketika orang lain secara sengaja maupun tidak sengaja menghirup udara yang mengandung percikan dahak infeksius tersebut. Kejadian penyakit TB di Puskesmas Cikupa periode Januari-Juni 2021 mengalami peningkatan dibandingkan periode yang sama tahun 2021 yaitu meningkat sebanyak 37 kasus (53 kasus menjadi 80 kasus baru).

\section{Tujuan}

Kegiatan pengabdian yang kami lakukan ini bertujuan bisa meningkatkan pengetahuan masyarakat di Cikupa sehingga dapat mengubah sikap dan perilaku masyarakat yang akhirnya diharapkan dapat menurunkan angka kejadian tuberkulosis.

\section{Metode}

Kegiatan pengabdian yang kami lakukan ini dengan memberikan penyuluhan kepada warga yang datang ke Puskesmas Cikupa. Sebelum kegiatan berlangsung, kami melakukan pre-test kepada warga yang hadir, kemudian penyuluhan dilakukan dengan media Power Point yang berisikan pengertian, penyebab, faktor risiko, cara penularan, gejala, pengobatan, dan cara pencegahan tuberkulosis. Setelah penyuluhan dibagikan leaflet dan dilakukan demonstrasi cara etika batuk serta penggunaan masker yang baik dan benar, kemudian kegiatan ditutup dengan post-test.

\section{Hasil}

Hasil pada 30 responden didapatkan adanya perbedaan rata-rata yang signifikan $(\mathrm{P}<0.001)$ antara nilai pretest dan postest dengan nilai mean difference sebesar 16,00 (SD 12,76). Hasil dari demonstrasi yang dilakukan juga baik dengan dilihat dari warga yang terpilih untuk melakukan demonstrasi ulang dapat mengulang cara etika batuk serta penggunaan masker yang baik dan benar. 


\section{Kesimpulan}

Kegiatan intervensi yang kami lakukan berjalan dengan baik dan sesuai rencana karena didapatkan peningkatan hasil nilai pre test dan post test sehingga kegiatan seperti ini dapat terus berlangsung untuk memberikan dampak khususnya penurunan kasus Tuberkulosis.

Kata Kunci: Tuberkulosis, Etika Batuk, Masker.

\section{A B S T R A C T}

\section{Background}

Tuberculosis (TB) is still one of the health problems in the community that can cause high morbidity, disability and death so that prevention efforts need to be made. Infection will occur when other people intentionally or unintentionally inhale air containing the infectious phlegm. The incidence of TB at the Cikupa Health Center for the January-June 2021 period has increased compared to the same period in 2021, which increased by 37 cases (53 cases to 80 new cases).

\section{The purpose}

The purpose of this service activity that we carry out is aimed at increasing community knowledge in Cikupa so that it can change people's attitudes and behavior which is ultimately expected to reduce the incidence of tuberculosis.

\section{Methods}

This service activity that we do is by providing counseling to residents who come to the Puskesmas Cikupa. Before the activity took place, we conducted a pre-test to the residents who were present in the Puskesmas, then counseling was carried out using Power Point media which contained the understanding, causes, risk factors, modes of transmission, symptoms, treatment, and ways to prevent tuberculosis. After the counseling, leaflets were distributed and demonstrations were held on cough etiquette and proper use of masks, then the activity was closed with a post-test.

\section{Results}

The results for 30 respondents found that there was a significant average difference $(\mathrm{P}<0.001)$ between the pretest and posttest values with a mean difference of 16.00 (SD 12,76). The results of the demonstrations carried out were also good,as seen from the residents who were elected to redemonstrate. They were able to shwo the proper cough etiquette and how to use masks properly and correctly.

\section{Conclusion}

The intervention activities that we carried out went well and according to plan because we got an increase in the results of the pre-test and post-test scores so that activities like this can be continued to have an impact, especially in reducing Tuberculosis cases.

Keywords: Tuberculosis, Cough Etiquette, Mask. 


\section{PENDAHULUAN}

Masalah kesehatan dalam komunitas masyarakat sangat beraneka ragam termasuk salah satunya adalah Tuberkulosis. Tuberkulosis masih menjadi masalah kesehatan masyarakat yang menimbulkan kesakitan, kecacatan dan kematian yang tinggi sehingga perlu dilakukan upaya penanggulangan. Tuberkulosis (TB) adalah penyakit menular yang disebabkan oleh Mycobacterium tuberculosis yang dapat menyerang paru dan organ lainnya. Menurut WHO tuberkulosis adalah masalah kesehatan global yang utama. Hal ini menyebabkan buruknya kesehatan di antara jutaan orang setiap tahunnya.

Penyakit TB merupakan penyakit menular langsung yang dapat disebabkan oleh kuman Mycobacterium tuberculosis. Penularan dapat terjadi ketika pasien yang didiagnosis TB sedang batuk atau bersin lalu kuman Mycobacterium tuberculosis tersebar ke udara dalam bentuk percikan dahak (droplet nuclei).

Berdasarkan data dari Kementrian Kesehatan Indonesia tahun 2021, estimasi kasus TB di Indonesia sebesar 845.000 kasus. Data tahun 2018, menunjukkan provinsi Banten memiliki jumlah penderita TB terbanyak di Indonesia. Berdasarkan data dari Dinas Kesehatan Kabupaten Tangerang.

Pada tahun 2018, wilayah Puskesmas Cikupa (240 kasus) memiliki kasus Tuberkulosis yang terbanyak di Kabupaten Tangerang setelah Puskesmas Kutabumi (242 kasus). Dan berdasarkan data yang terkini, angka kejadian penyakit TB periode Januari-Juni 2021 mengalami peningkatan dibandingkan periode yang sama tahun 2021 yaitu meningkat sebanyak 37 kasus (53 kasus menjadi 80 kasus baru).

Proses pendidikan dapat mengubah sikap serta tata laku seseorang atau kelompok orang dan juga dapat mendewasakan cara berpikir dari sekelompok orang. Hal ini dapat diperoleh melalui upaya pengajaran dan pelatihan. Salah satu proses pendidikan yang singkat dapat dilakukan melalui penyuluhan. Penyuluhan dapat meningkatkan pengetahuan masyarakat. Di Puskesmas Cikupa sendiri, penyuluhan tuberkulosis jarang dilakukan, karena itu kami ingin berinisiatif melakukan penyuluhan tentang program tuberkulosis di Puskesmas Cikupa.

Faktor-faktor yang menyebabkan terjadinya tuberkulosis seperti: usia, jenis kelamin, merokok, kepadatan hunian, pekerjaan, status ekonomi, dan penyakit penyerta. Banyaknya faktor resiko membuat masyarakat harus mengetahui lebih dalam mengenai tuberkulosis.

Masyarakat mengetahui bahwa cara menggunakan masker merupakan cara yang terbaik dalam mencegah penularan penyakit yang menular melalui udara. Tetapi masyarakat tidak tahu bagaimana cara menggunakan masker yang baik dan benar. Begitu pula, etika batuk menjadi salah satu solusi permasalahan yang ada sehingga masyarakat akan juga diajarkan cara etika batuk yang baik dan benar)

\section{METODE}

Langkah awal yang digunakan adalah dengan menganalisis masalah apa saja yang ada di Puskesmas Cikupa. Puskesmas Cikupa berada di Kecamatan Cikupa, Kabupaten Tangerang, Provinsi Banten dengan luas wilayah 43.407 km2. Wilayah kerja Cikupa terdiri dari 9 desa dan 1 kelurahan (Desa Cikupa, Desa Talaga, Desa Talagasari, Desa Cibadak, Desa Sukanegara, Desa Bojong, Desa Budimulya, Desa Dukuh, Desa Bitungjaya, dan Kelurahan Sukamulya).

Setelah dilakukan analisis masalah, maka dilakukan identifikasi penyebab masalah dengan Paradigma Blum. Paradigma Blum terdiri dari identifikasi penyebab masalah melalui sudut pandang genetik, layanan kesehatan, gaya hidup, dan lingkungan. Untuk mendapatkan data-data ini, dilakukan mini survey. Dari hasil mini survey didapatkan bahwa pengetahuan dan perilaku terhadap TB masih kurang. 
Penentuan prioritas masalah dilakukan dengan teknik non-scoring Delphi dengan cara berdiskusi dengan kepala puskesmas, dokter, dan perawat yang bertugas di Puskesmas Cikupa.

\section{HASIL DAN PEMBAHASAN}

Hasil dari diskusi didapatkan bahwa faktor gaya hidup menjadi prioritas sehingga kami memutuskan untuk melakukan intervensi sehingga dapat menambah pengetahuan masyarakat terhadap TB. Intervensi ini diharapkan dapat merubah sikap dan perilaku masyarakat yang dapat mencegah penularan serta dapat menurunkan angka munculnya kasus TB baru. Berdasarkan identifikasi akar penyebab masalah menggunakan fishbone, maka dilakukan intervensi dengan melakukan penyuluhan tentang penyakit $\mathrm{TB}$, etika batuk dan cara menggunakan masker dengan baik dan benar, serta memasang poster dan standing banner mengenai penyakit TB.

Untuk mendukung kegiatan tersebut, tahap awal yang dilakukan adalah penyampaian materi mengenai tuberkulosis dalam bentuk pemaparan menggunakan Power Point. Tahap awal ini berisi penjelasan yang terdiri dari definisi, penyebab, faktor risiko, cara penularan, gejala, pengobatan, dan cara pencegahan. Setelah kegiatan penyampaian materi, dibagikan leaflet yang berisikan etika batuk dan cara menggunakan masker yang baik dan benar. Untuk kegiatan ini, dijelaskan isi leaflet dengan mendemonstrasikan etika batuk dan cara menggunakan masker yang baik dan benar. Setelah peserta memahami dengan baik, kemudian perwakilan warga dipilih secara acak untuk dapat memperagakan etika batuk dan cara menggunakan masker yang baik dan benar, langsung di hadapan penyuluh dan responden.

Sebelum kegiatan berakhir, diadakan post-test untuk melihat seberapa besar efektivitas dari kegiatan intervensi yang dilakukan. Hasil dari 30 responden dianalisa dengan metoda paired t-test. Dari sini didapatkan adanya perbedaan rata-rata yang signifikan $(\mathrm{P}<0.001)$ antara nilai pretest dan postest dengan nilai mean difference sebesar 16,00 (SD 12,76). Acara kemudian ditutup dengan pemberian hadiah terhadap peserta yang bisa memperagakan etika batuk dan cara menggunakan masker yang baik dan benar dan juga yang memiliki nilai peningkatan post test disbanding pre test yang terbanyak.

Kendala yang dihadapi adalah beberapa peserta tidak mengikuti acara dari awal sampai selesai. Ada peserta yang terlambat datang, ada peserta yang pulang lebih awal, dan juga ada peserta yang menolak untuk mengisi pre-test dan posttest yang kami bagikan. Walaupun terdapat kendala, tetapi kegiatan yang dilakukan ini tidak mengalami hambatan dan masih dapat berlangsung dengan baik.

Untuk Puskesmas Cikupa sendiri, diberikan poster dan standing banner, sehingga warga yang berkunjung di Puskesmas Cikupa juga bisa membaca dan melihat poster dan standing banner yang kami pasang. Dengan fasilitasi ini, secara tidak langsung para pengunjung Puskesmas Cikupa juga dapat meningkatkan pengetahuan mereka mengenai pengendalian Tuberculosis. Kesulitan yang dialami dalam pemasangan poster dan standing banner adalah menentukan titik pemasangan poster karena terbatasnya tempat pemasangan dan standing banner di area Puskesmas Cikupa. Kendala tersebut dapat diatasi dengan bantuan dan saran dari kepala poli TB sehingga poster dan standing banner dapat dipasang di tempat yang mudah di baca oleh warga yang berkunjung ke Puskesmas Cikupa, terutama pasien tuberkulosis.

Pada saat kegiatan berlangsung, dilakukan monitoring dan setelah kegiatan berlangsung kami melakukan evaluasi dengan pendekatan sistem. Dari hasil evaluasi didapatkan bahwa kegiatan yang dilakukan tidak memiliki kesenjangan yang berarti sehingga dapat dikatakan bahwa kegiatan ini telah berhasil dilaksanakan dengan baik. Berikut adalah karakteristik responden dari peserta penyuluhan yang diikuti oleh grafik hasil pre-test dan post-test dari peserta penyuluhan serta foto-foto saat dilakukannya acara penyuluhan di Puskemas Cikupa. 
Table 1. Karakteristik Responden Peserta Penyuluhan

\begin{tabular}{|c|c|c|}
\hline & $\mathbf{n}(\%)$ & $\operatorname{mean}(\min , \max )$ \\
\hline \multicolumn{3}{|l|}{ Jenis Kelamin } \\
\hline Laki-laki & $15(50)$ & \\
\hline Perempuan & $15(50)$ & \\
\hline Usia (tahun) & & $33(17,60)$ \\
\hline $11-20$ & $2(6,7)$ & \\
\hline $21-30$ & $14(46,7)$ & \\
\hline $31-40$ & $6(20)$ & \\
\hline $41-50$ & $6(20)$ & \\
\hline $51-60$ & $2(6,7)$ & \\
\hline \multicolumn{3}{|l|}{ Pendidikan } \\
\hline SMP & $5(16,7)$ & \\
\hline SMA/SMK & $22(73,3)$ & \\
\hline S1 & $3(10)$ & \\
\hline \multicolumn{3}{|l|}{ Pekerjaan } \\
\hline Tidak Bekerja & $14(46,7)$ & \\
\hline Bekerja & $16(53,3)$ & \\
\hline
\end{tabular}

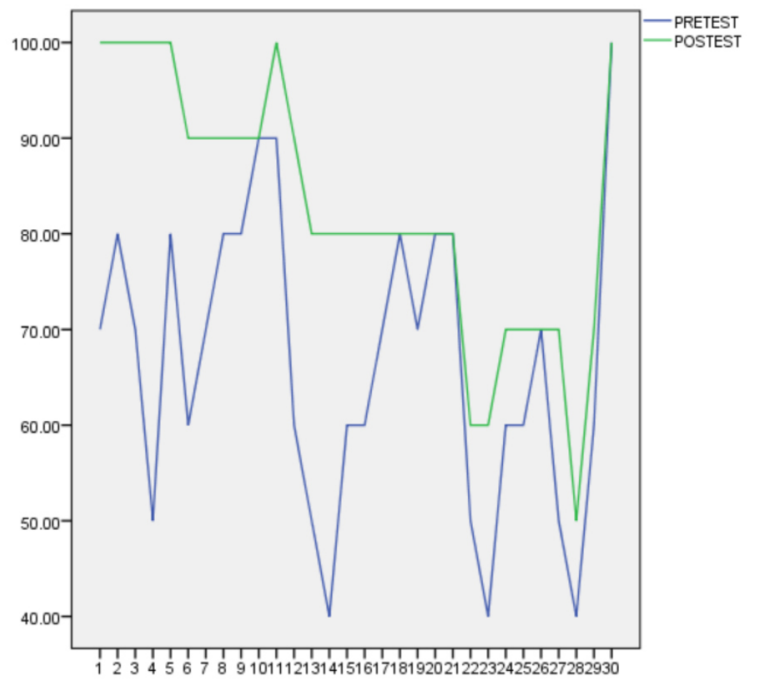

Gambar 1. Grafik perbandingan hasil pre-test dan post-test
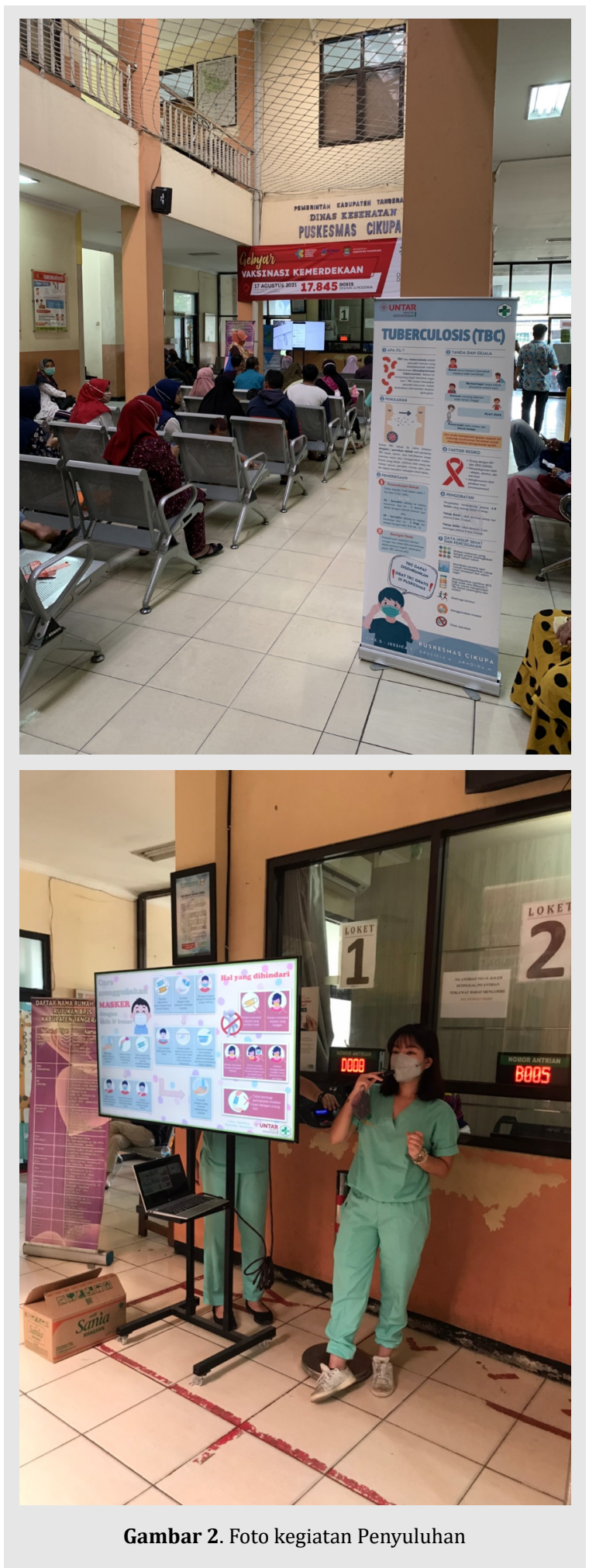

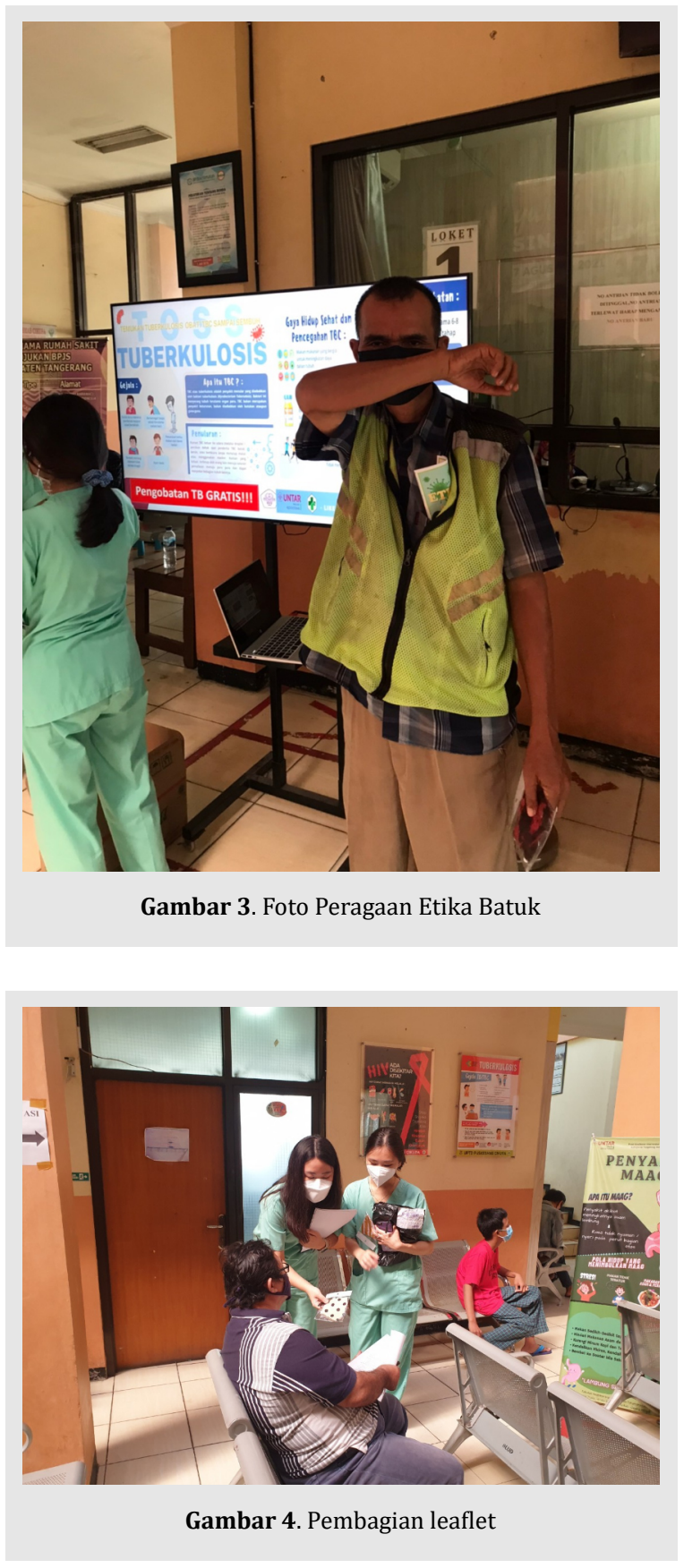

\section{KESIMPULAN DAN SARAN}

Kegiatan-kegiatan dalam upaya menurunkan kasus tuberkulosis ini sangat diperlukan serta sebaiknya dilakukan secara berkesinambungan karena bahaya akibat peningkatan kasus akan mengakibatkan penurunan kualitas hidup serta akan meningkatkan biaya yang dibutuhkan untuk melakukan pengobatan. Kegiatan penyuluhan ini dapat dikatakan berhasil karena terdapat peningkatan pengetahuan yang dapat dilihat dari hasil nilai pretest dan posest. Dari hasil pada 30 responden, terlihat adanya perbedaan rata-rata yang signifikan $(\mathrm{P}<0.001)$ antara nilai pre-test dan pos-test dengan nilai mean difference sebesar 16,00 .

Kasus tuberkulosis masih merupakan kasus yang perlu mendapatkan perhatian dari berbagai pihak. Kegiatan guna menurunkan kasus tuberkulosis sangat dibutuhkan dan sebaiknya dilakukan secara berkelanjutan. Dibutuhkan kerjasama dari banyak pihak dan upaya yang berkelanjutan agar dapat menurunkan tingkat penderita tuberkulosis. Peran pendidik dan mahasiswa kedokteran juga sangat penting.

Kegiatan intervensi telah berjalan dengan baik dan sesuai dengan rencana serta diharapkan kegiatan seperti ini dapat terus berlangsung di Puskesmas Cikupa, agar dapat memberikan dampak yang cukup berarti dalam bentuk penurunan kasus Tuberkulosis. Jika tuberkulosis tidak ditangani dengan serius maka akan terjadi penularan yang sangat cepat sehingga dapat menurunkan kualitas kesehatan masyarakat. Kegiatan semacam ini bisa dilaksanakan oleh semua pihak sehingga bisa lebih meningkatkan pengetahuan masyarakat mengenai tuberkulosis. Diharapkan juga penyuluhan ini dapat meningkatkan sikap dan perilaku masyarakat agar melakukan tindakan pencegahan penularan terhadap tuberkulosis. Hasil akhir yang diharapkan adalah terjadinya perubahan sikap yang berdampak pada penurunan kasus Tuberkulosis.

Ucapan terimakasih disampaikan kepada semua pihak yang telah berpartisipasi dalam kegiatan ini sehingga acara penyuluhan dapat berlangsung dengan baik dan sesuai dengan rencana. Ucapan Terimakasih ini disampaikan khususnya kepada Rektor beserta Jajarannya, Lembaga Penelitian dan Pengabdian Masyarakat Universitas Tarumanagara atas pembiayaannya, Pimpinan Fakultas Kedokteran Universitas Tarumanagara, Dinas Kesehatan Kabupaten Tangerang serta Puskesmas Cikupa atas partisipasinya. Atas partisipasi dari semua pihak, acara ini telah dapat terselenggara dengan sukses. 


\section{R E F E R E N C E}

Departemen Kesehatan RI. (2015). Pedoman Nasional Penanggulangan Tuberkulosis. Depkes RI. Jakarta: Direktorat Bina Kesehatan Masyarakat.

Dinkes (2019). Profil Banten. J Phys A Math Theor.2019;44(8):1689-99

Kemenkes RI (2015). Petunjuk Teknis Manajemen dan Tatalaksana Tuberkulosis Anak. Kementrian Kesehatan RI. Jakarta: Kementrian kesehatan RI

Kementrian Kesehatan RI (2018). Profil Kesehatan Indonesia 2018. Jakarta: Kementrian Kesehatan RI

PDPI. (2011). Tuberkulosis Pedoman Diagnosis dan Penatalaksanaan di Indonesia. Indah Offset Citra Grafika. Jakarta

Sejati A, Sofiana L. (2015) Faktor-faktor Terjadinya Tuberkulosis. J Kesehat Masy.Jakarta

Soemirat (2010). Epidemiologi, Wabah Penyakit, Lingkungan, Sumber Daya Alam. Yogyakarta: Universitas Gadjah Mada.

Sudoyo, Aru W, dkk. (2007). Buku Ajar Ilmu Penyakit Dalam. Edisi 4, Jilid 1. Jakarta: Departemen Ilmu Penyakit Dalam FK UI. 